\title{
La enorme mentira y la gran verdad de la información en tiempos de la postverdad
}

The huge lie and the great truth of information in times of after truth

\author{
Juan Carlos Marcos Recio (1), Juan Miguel SÁnchez Vigil (2), María Olivera Zaldua (3) \\ (1) Facultad de Ciencias de la Información de UCM, Av. Complutense s/n 28040, jmarcos@ucm \\ (2) Facultad de Ciencias de la Documentación de UCM, C/ Stma. Trinidad 37 28010, jmvigil@ucm.es (3) molivera@ucm.es
}

\begin{abstract}
Resumen
Los tiempos presentes en los que la producción de contenidos es tan alta, dispersa y divergente, no permite a los ciudadanos reflexionar sobre lo que se escribe, quién lo hace o dónde se originó la idea principal. Acostumbrados al placer de disfrutar una información por más de 24 horas, que era el tiempo de valor de las noticias en el siglo XX, y pasar al siglo actual donde apenas dura unas horas, conlleva un ejercicio el determinar que toda la información que circula es verdad. Estamos en tiempos de la postverdad, donde las redes sociales mandan porque el consumo mayoritario se logra en ellas. Los medios han cedido un testigo que les convertía en referentes informativos y además generadores de opinión pública. El reto no es conseguir información, ahora el valor está en las fuentes, aunque la mayoría de los usuarios prefieren la rapidez que les ofrecen las redes sociales y en organizar el conocimiento en ellos, frente a la veracidad de los medios tradicionales.
\end{abstract}

Palabras clave: Postverdad. Medios de comunicación. Redes sociales. Control de información. Mentira. Facebook.

\section{Introducción}

Una industria de noticias fuerte también es crítica para construir una comunidad informada. Dar a la gente una voz no es suficiente sin tener personas dedicadas a descubrir nueva información y analizarla. Hay más que debemos hacer para apoyar a la industria de las noticias y asegurarnos de que esta función vital y social sea sostenible. (Mark Zuckerberg, 2017)

Los grandes políticos han sido quienes mejor han entendido el concepto de verdad. Incluso, por encima de los filósofos y de los comunicadores. Para ellos, la verdad, su verdad, la que hacen creer al resto de ciudadanos, es la que importa. $Y$ dedican grandes esfuerzos a demostrarlo, con infinidad de teorías y dando las suficientes vueltas como para que sea creíble. Una mentira solitaria queda en eso. Una mentira contada miles, millones de veces se convierte en una verdad, creíble cuando la confianza en determinados medios es total. Y aquí ya entran en juego las redes sociales. Antes presentamos la situación anterior a su llegada.

\begin{abstract}
The present times, in which the production of content is so high, dispersed and divergent, does not allow citizens to reflect on what is written, who does or where the main idea originated. Accustomed to the pleasure of enjoying information for more than 24 hours, which was the value time of the news in the twentieth century, and moving to the current century where it lasts only a few hours, entails an exercise to determine that all the information that circulates is true. We are in the times of the future, where social networks rule because the majority consumption is achieved in them. The media have yielded a witness that made them informative referents and also generators of public opinion. The challenge is not to get information. Now the value is in the source, although the majority of the users prefer the speed that they offer the social networks against the veracity of the traditional means.
\end{abstract}

Keywords: Post truth. Media. Social networks. Information control. Lies. Facebook.

Nadie está en poder de la verdad absoluta. Y menos los medios de comunicación. La llegada de tecnologías de uso y control masivas está permitiendo importantes cambios en la manera de comunicar que tienen las personas. Deberíamos preguntarnos y aproximarnos en este texto a esta cuestión: ¿Qué vale más un consejo de alguien próximo a la persona o miles y miles de comentarios de gente que no conoces de nada pero que te apoyan con un "me gusta"? La respuesta parece estar más cerca de la segunda versión. EI narcisismo es un camino galopante que recorre la sociedad actual. Los más jóvenes, muchos de ellos aislados en su propio mundo, en una sociedad que tiene otros intereses, descubren con gran satisfacción que hay otras realidades fuera, que además atienden sus peticiones, esas que en sus círculos próximos no toman en serio. Se sienten identificados en los mundos paralelos de las redes sociales, donde buscan la reafirmación de su yo y la constatación de que otros viven también esas experiencias. En algunos casos, esas propuestas terminan en una visión trágica de la 
vida. Para identificarse requieren de extremismos que graban como testimonio de su propia necesidad, antes de tomar una drástica decisión.

Hasta la llegada de las redes sociales fueron los medios de comunicación el gran espejo de la sociedad. Aparecer o no en ellos era símbolo de estatus. Lo que hacían los medios, la forma en que construían la información y los métodos empleados para hacer una sociedad más democrática, justa y participativa era una prerrogativa de los periódicos impresos, primero y, luego, de la televisión. El siglo $X X$, sobre todo después de la segunda Guerra Mundial, se edifica en base a la sociedad que descubre la televisión. Un mundo irreal que invita a los ciudadanos a que lo tomen como real. Es una mentira rodeada de verdad que crea mundos paralelos y que los ciudadanos están dispuestos a validar. Y el cine vino a refrendar esas teorías, añadiendo una gran parte de glamour que llevaba a los espectadores, por un par de horas y unos cuantos dólares al paraíso, del que luego eran expulsados a su propia realidad.

Sin embargo, está en la naturaleza del ser humano ser cambiantes y oponerse a situaciones que no son tan auténticas como se ven reflejadas en los medios de comunicación. Y apostaron entonces por creer que esa tecnología que es tan buena para la ciencia, los hospitales, el ocio y el entretenimiento, no lo era tanto para los medios de comunicación que se vieron desplazados por las redes sociales. Éstas vinieron a ser el espejo en el que se miran desde entonces las generaciones más jóvenes y, también porque no decirlo, los que antaño soñaron con verse dentro del paraíso de la TV y del cine.

Pero nadie calculó las consecuencias. Solo importaba el número. Cuantos más mejor. Todo era gratis, con la condición de que se añadiera lo que importaba para que otros hicieran lo mismo y se construyera una gran colmena. Eso son las redes sociales, una colmena, manejada por una reina a la que todos alimentan con su esfuerzo. Te ofrecen el paraíso para que vivas en él, siempre y cuando aportes fotos, textos, etc., propios y o extraños que puedes compartir.

La democracia, más o menos controlada desde la televisión en las campañas políticas, cedió el testigo a esas redes; incluso, se especuló que la victoria del candidato Trump se debió a la información privilegiada en el manejo de esas redes. La economía se volvió más centralizada que nunca y su poder creo tentáculos tan poderosos que ya no se sabe bien quién mueve los hilos de las empresas dentro de los países, ya que muchas de ellas se han deslocalizado, aprovechando otros salarios en lugares donde la sociedad permite que el pago sea escaso. La vida en toda su dimensión se adaptó a lo que las grandes corporaciones (casi todas de Estados Unidos) nos invitaban a probar. Así, el mundo pasó de un Plan Marshall a un Plan Zuckerberg. El producto era diferente porque las necesidades también lo eran.

También este planteamiento de buscar la verdad es necesario para organizar el conocimiento. No se puede dar como válida la información y al tiempo decir lo contrario. Los errores que se producen en los medios de comunicación tienen una especial significación; aunque más tarde se obligue por ley a la rectificación, no todos los usuarios de ese medio se dan cuenta. En este sentido es clave la función de la hemeroteca (tradicional o digital) y en consecuencia la técnica para organizar los documentos conservados con el fin de facilitar el acceso, es decir de globalizar.

En este orden del mundo se ha elaborado un calendario de mentiras y verdades que se manejan al antojo de los políticos y las corporaciones que los respaldan. No es nada nuevo. Se trata de seguir creando mundos para que el ser humano se identifique con su propia felicidad y viva inmerso en ella. El reto es para los medios de comunicación. Ellos deben destapar las verdades ocultas y las mentiras ciertas. Cuando de verdad aportan valor y construyen un mundo de igualdad es cuando están respondiendo a este enunciado: la enorme mentira y la gran verdad deben resolverse para ofrecer al ciudadano lo que el mundo está construyendo, lo que sucede a escasos kilómetros, pero también lo que les afecta cuando a lo lejos una empresa quiebra y no tarda en pasar lo mismo en su ciudad.

\section{Las redes mandan, la información ya no tanto}

Más de un siglo de dominio de los medios de comunicación escritos sirvieron para ir construyendo sociedades democráticas, que sin embargo no impidieron dos guerras mundiales y otras tantas en países que nunca habían tenido un conflicto. Los periódicos, que también ayudaban a crear guerras y luego luchaban por detenerlas, estaban por encima de la verdad y de la mentira. $Y$ así siguen actuando en la actualidad, aunque menos. Buscaban siempre la cara amable de la sociedad, el referente de una razón fundamentada en la verdad. Mientras que los periódicos impresos dominaron el mundo, con millones de ejemplares saliendo de las rotativas, la sociedad lectora servía para justificar los condicionantes de la información. Situémonos en 1898, cuando William Random Hearst, uno de los grandes magnates de la prensa de entonces, que había enviado a uno de sus dibujantes a Cuba y 
éste quería regresar a Estados Unidos porque no encontraba nada interesante ni noticioso que dibujar, recibió un telegrama de su jefe: "Tú haz los dibujos, que yo pondré la guerra". Y así fue. Poco tiempo después, el New York Journal anunciaba un nuevo conflicto entre España y Estados Unidos con un claro vencedor desde el comienzo.

Si se analizan los principales periódicos del siglo $\mathrm{XX}$, a lo largo de las confrontaciones que hubo, se descubre con mediana claridad que las enormes mentiras y las grandes verdades conviven con cierta naturalidad. Lo que se viene a denominar propaganda de guerra, que incluye también en el siglo $X X$ a la radio y a los pasquines que se lanzaban desde lo aviones, se fue transformando en otra manera de contar lo que sucedía en esos conflictos. Y al finalizar los mismos se puede valorar cuánto de verdad hubo de información y cuanto de manipulación o propaganda a favor de la causa.

Mientras los periódicos impresos perdían fuerza, la televisión se convirtió en la "reina" de las noticias que el mundo deseaba recibir en conflictos más recientes, como la Guerra de Irán e Irak, o la caída de Sadam Hussein años después. Y fue entonces cuando la cadena CNN tuvo el privilegio de informar, una vez que todos los medios fueron obligados a salir del país. El control absoluto del régimen político solo permitía obtener una única versión, por muy independientes que fueran sus periodistas. Algo no muy diferente es lo que ha pasado estos días cuando este mismo medio fue expulsado de Venezuela.

Este tiempo de la televisión está pasando a mejor vida. La mayoría de los ciudadanos que siguen la información en este medio no tienen como prioridad estar informados, sino profundizar en alguna información que la televisión ha preparado y pone en su sitio web como contenido informativo. Ya no es un referente de actualidad. ¿Dónde se informan los ciudadanos? ¿Cuál es el medio predominante? ¿Qué tipo de informaciones se ofrecen? ¿Qué hay de verdad y que no? ¿Existe un manejo de fuentes que nos permitan creer en la verdad de la información? ¿Qué tipo de documentos se generan? ¿Cómo se organizan los nuevos documentos?

No hay respuestas milagro para este nuevo entorno. Estamos en tiempos de la postverdad. Pensemos en que antes una información tenía al menos una vigencia de 24 horas. Tiempo suficiente como para contrastar bien lo que se iba a publicar. Buscar las causas y consecuencias de la información, reflexionar sobre los hechos y madurar a la hora de escribir las mejores ideas. En la actualidad, esa misma información se viene cambiando, mejorando y actualizando varias veces al día. En ese caso, con más razón. Si los periodistas disponen de herramientas que les permiten cambiar, actualizar y ofrecer nuevos contenidos de una misma información, ¿cómo es que en el mundo cada vez hay más noticias falsas? El reciente triunfo de Trump en la presidencia de los Estados Unidos es un ejemplo claro de lo que la verdad esconde y de lo que la mentira afirma.

El mundo es de las redes sociales. Una gran crisis de identidad viene afectando a los periódicos y al resto de medios desde hace dos décadas. Hasta entonces, la mayoría de las noticias procedían de un pequeño núcleo de corporaciones de medios que eran capaces de llegar a un gran público. Se trataba de unas cuantas agencias de noticias a nivel global y varios grupos de comunicación con poder para obtener informaciones en todo el mundo y construir su propia verdad. Lo hacían sin competencia, o al menos con un Estado en el que todos tenían acceso a la publicidad que les permitía, además de las subvenciones, seguir adelante. Pero también tuvieron que asumir la crítica de la sociedad o de algunos sectores y/o personas influyentes. Así Chomsky y Herman fungieron con su espíritu crítico: "la materia prima de la noticia debe pasar a través de filtros sucesivos, dejando sólo el residuo limpio y apropiado para imprimir". El resultado, como señala Tanz, fue un falso consenso nacional, que ignoró hechos, voces e ideas periféricas. (Tanz, 2017).

Hasta entonces, y este entorno es la parte fundamental de lo que está sucediendo en la actualidad, los medios estaban al servicio, más o menos, de los dirigentes políticos que los subvencionaban o apoyaban con informaciones que hacían crecer sus audiencias/lectores. Los grandes debates de cierre de elecciones, aplicados primero en Estados Unidos, y luego replicados en otros países occidentales, llegaron a su fin (aunque se sigan haciendo) en la primera década del siglo $\mathrm{XXI}$. A modo de resumen, las redes sociales se fueron apoderando del entorno político de la siguiente manera: 2008, "Elección de YouTube" y "Facebook", ya que las dos plataformas fueron muy utilizadas por el personal de Barack Obama para transmitir sus mensajes; 2012 pasó a la historia como la elección Twitter, gracias a los tweets como los legendarios "Cuatro años más"; y 2016, ascenso de todas las plataformas sociales, llega Instagram, aplicaciones en vivo (Hillary Clinton y Ted Cruz) y Snapchat.

Lo que algunos medios de comunicación no han entendido es que esa cadena se ha roto. No son tan importantes como antaño. Los políticos ya no necesitan a los medios, ya no dependen de los 
periodistas para llegar a sus audiencias. Ahora pueden hablar directamente con ellos o comunicar desde las webs informativas de las instituciones públicas y privadas (Salvador Benítez, Sánchez Vigil 2016). En estos momentos, la comunicación es directa con los votantes, sin el tamiz de la televisión. Y lo más importante: reciben una respuesta directa, la estudian y saben qué tienen que ir cambiando en su estrategia comunicativa. Al mismo tiempo perciben qué otras personas están alejadas de su perfil votante y pueden construir de manera directa para ellos, para convencerles desde una misma posición.

Mientras que los periódicos y la televisión eran un filtro difícil de superar para los votantes, ahora, las redes sociales mandan porque son interactivas y porque el seguidor de esas redes se siente en constante comunicación con el candidato. Y esto que se aplica en los procesos electorales también se utiliza en el mundo de la empresa, el entretenimiento, el comercio, etc. No es arriesgado decir que esta revolución de las redes sociales donde el poder está abajo, frente al poder de la pirámide que controlaban los grupos económicos que movían los hilos políticos, ha perfilado una nueva sociedad que aún no se puede catalogar porque los resultados están por verse. En todo caso, y en relación a los medios de comunicación, perdieron el poder y sólo sobrevivirán si saben adaptarse a los tiempos y utilizan las redes sociales en beneficio propio. Los lectores de papel se reducen considerablemente. Un periodista publica una historia y aunque la lean miles de personas, nunca llegará a crear estado de opinión porque serán una minoría frente a la gran masa que ha leído en las redes sociales otro texto y ese será el que dé valor a la sociedad cuando se mueva por las redes. Si un periodista no es capaz de compartir su texto y de que las redes sociales como un espejo lo ofrezcan, aquél no pasará a la historia. Así pues, las redes mandan, la información no tanto.

Cuestión fundamental en el cambio es la modificación de los documentos, los nuevos modelos que circulan por las redes, generalmente multimedia, lo que influye en la organización del conocimiento, y en el diseño de herramientas y técnicas para el tratamiento documental; es decir, que debe prestarse mayor atención al tema debido a la profusión de contenidos.

\section{La influencia del periodismo no es la que era}

El constante trasvase de lectores hacia las redes sociales, de aquellos que abandonan la televisión por YouTube, de los que no consumen revistas porque han encontrado en Snapchat y/o Instagram los recursos que necesitan para ser "glamurosos" o de los que escuchan radios nativas en digital frente a las grandes cadenas, dibujan un periodismo diferente en su concepción. El camino se ha recorrido dando pasos de gigante por parte de las redes sociales y muy tímidos por el resto de los medios. El empuje, lejos de venir de periódicos con gran poder, enraizados en la sociedad; de televisiones con audiencias millonarias o de radios con miles de seguidores, lo dieron las propias redes. En muchos casos ha sido un proceso autoproclamado al ver que los medios fueron dejando un campo abierto al consumo de noticias.

Casi sin darse cuenta y pero conscientes de la realidad, algunas redes sociales se encontraron con millones de personas que aceptaban contenidos informativos que los propios usuarios ofrecían como suyos. Mientras el periodismo digital jugaba al periodismo ciudadano, las redes sociales afrontaban el reto de aceptar lo que sus usuarios querían mostrar a otras personas. Entonces, el periodismo enrabietado comenzó una guerra contra ellas. No es periodismo si no tiene suficientes datos, no lo es cuando no está contrastado, cuando no tiene declaraciones de los protagonistas, etc. Pero para los usuarios de las redes era información. ¿Qué separa/une a la información y el periodismo? El periodismo sin información no es periodismo. Los medios tenían los datos, las declaraciones, la profesionalidad del periodista, pero no encontraban lectores que consumieran esa información. Las redes carecían de todo lo anterior, pero ofrecían informaciones que para la mayoría de los usuarios eran suficientes.

En este compromiso se vieron los lectores de Google News. Estaban suficientemente informados. Cuando de verdad querían ampliar la información, a través de un enlace llegaban a los propios medios para completar la lectura. En este caso, ambos medios se complementaban. Google News arrastraba su audiencia hacia el medio y éste obtenía más lectores y consecuentemente más publicidad.

Facebook es algo diferente, si bien nunca se ha posicionado como un medio de comunicación, si que han valorado que algunas propuestas de sus usuarios se podrían comparar con contenidos informativos. Pero, lejos de enfrentarse a los grandes medios de comunicación, su CEO y fundador pasó a desmentir esa propuesta cuando algunos medios informaron que estaban haciendo información: "Cuando piensas en una compañía de medios, ya sabes, la gente está produciendo contenido, la gente está editando contenido, y eso no es lo que nosotros hacemos" (Zuckerberg, 2017). 
Más recientemente aclaró esta idea en un memorándum que publico en Facebook; o más bien, abrió nuevas brechas al señalar que era difícil para los medios sobrevivir en un mundo que domina Facebook (LaFrance, 2017):

Ahora, Zuckerberg está dejando claro que quiere que Facebook tome el control de muchas de las funciones reales - no sólo los dólares de publicidadque las organizaciones de noticias tradicionales tuvieron una vez. Zuckerberg está construyendo una organización noticiosa sin periodistas.

Algunos periodistas han visto en este manifiesto una manera de destruir el periodismo; al menos, el que ha venido apoyando a la democracia, a la construcción de sociedades más justas y a una mejor convivencia entre las personas.

Lejos de tranquilizarse, los medios entendieron que era una manera de acercar posturas, pero nada se clarificaba porque mientras Facebook sigue creciendo por millones de usuarios, los lectores y las redacciones están descendiendo a pasos agigantados. Los medios de comunicación están en un problema. Es un problema propio en el que las redes sociales no tienen la culpa, como explica Tanz (2017):

El modelo de negocio impulsado por la publicidad está al borde del colapso. La confianza en la prensa está en uno de los puntos bajos de todos los tiempos. $Y$ ahora esas dos preocupaciones largas se han sumado a una crisis existencial aún mayor. En una era post-hecho de noticias falsas y burbujas de filtro, en las cuales el público selecciona la información y las fuentes que coinciden con sus propios sesgos y descarta el resto, los medios de comunicación parecen haber perdido su poder de moldear la opinión pública.

$Y$ lo que realmente quedaba a los medios del siglo XX era la manera en que podían crear y cambiar la opinión pública. Entre los medios y los usuarios había una excelente comunicación. Para los usuarios, porque respaldaban su propio pensamiento cuando se apoyaban en lo que habían leído en el periódico o visto en la televisión. Con frecuencia se oían expresiones como lo ha dicho tal periódico o lo he visto en los informativos de la televisión. Esa comunión funcionó por el interés y compromiso de ambas partes.

En el siglo XXI los consumidores de noticias no tienen deudas ni compromisos con los grandes medios. Entraron a convivir con las noticias digitales y muy pocos han tenido contacto diario con los medios cada día. Fue una puesta en común total. No necesitaban leer secuencialmente el periódico para estar informados. Lo estaban porque tenían abiertas sus principales redes sociales de las que obtenían las noticias. En ocasiones, cuando la noticia lo requería y después de pedir opinión a otros amigos o personas que estaban en su mismo círculo, pasaban a completar esa información en algún medio tradicional. Pero esa es una minoría insuficiente para mantener una tasa de usuarios alta que interese a las marcas que pueden poner publicidad en el medio. $Y$ hay que resolver otra cuestión que ya empieza a preocupar a los editores de prensa: generaciones que no han convivido nunca con los medios impresos y que ya están en el mercado (Tyner, 2017):

Para las personas como nosotros, que no crecimos con los periódicos y que hemos utilizado la Internet desde que éramos niños, muchas de las convenciones de las noticias de hoy no tienen sentido. Las noticias en 2017 no tienen que seguir el ciclo de producción de noticias en 1987, y tampoco deben venir en la misma forma. Adaptar un periódico para la web moderna no es lo suficientemente bueno para las personas que nunca leen los periódicos en primer lugar. Nos merecemos algo nuevo.

El cambio hacia un mundo más completo es un reto que no han resuelto los medios, especialmente los periódicos. Se ha intentado de varias maneras. Abrir el contenido del periódico, abrir una parte del mismo; combinar gratis con otra parte de pago; apostar por excelentes contenidos que atraigan lectores que hasta entonces solo buscaban la información en las redes sociales, crear muros de pago y zonas gratuitas, etc. En estos últimos veinte años hay una cuestión prioritaria: un buen producto informativo solo se consigue cuando un periodista logra hacer información de calidad. Otra cosa es que ese tipo de información termine por interesar a unos pocos, muy pocos. En ese caso, ese periódico, radio y/o televisión han de apostar por productos muy bien elaborados para un público selecto.

Esta información "gourmet" tiene su recorrido en determinados nichos de mercado que no llegan a cubrir los grandes medios. En ningún caso se puede comparar con las informaciones globales que tienen un gran recorrido en las redes sociales. Por ejemplo, la noticia de la muerte de un cantante de éxito o la situación de una "celebritie" da mucho juego como contenido noticioso en las redes sociales; pero quizás no tanto en un medio digital. A cambio, un gran descubrimiento científico sería muy valorado por los medios tradicionales que ampliarían la información preguntando a otros científicos y tomando información de prestigiosas revistas de esa área. El resultado sería de mucho valor para los seguidores de ese medio, pero muy pocos serían los que pasarían a comentarlo con sus amigos y conocidos en las redes.

No todo sucede exactamente así. Este es un ejemplo. El periodismo tradicional, con fuentes de información fiables, con métodos para contrastar la información y con rigurosidad a la hora de informar ha quedado al margen de lo que quieren los 
nuevos lectores. Frente a los lectores pasivos, con muy poca participación en los medios escritos del siglo $X X$, como mucho a través de las cartas al director o de algún artículo de opinión, se ha pasado a un lector crítico (Marcos et al., 2008) y actuante que comenta aquellas noticias que a su juicio tienen un valor para él y sus conocidos. Mientras, el resto de noticias, las que de verdad cuesta crear, esas no suelen despertar un interés en los miembros de una red social. No se trata de discriminar, ni de comparar. No son los buenos, los intelectuales, los comprometidos, etc., los que leen los periódicos tradicionales y ven programas de calidad en la televisión; ni a la contra, los que solo asumen la información a través de las redes son los mal informados, los que se dejan influir, los que creen que la verdad es esa y solo esa.

El cambio no ha resuelto esta dicotomía. Nunca antes (y eso que también se cometían errores) se han producido tantas noticias falsas (algunos artistas han muerto varias veces) ni se han juzgado de forma paralela a protagonistas de la información como cuando su historia aparece en alguna red social. La vida cambia y con ella el periodismo. $Y$ aunque haya perdido influencia en la sociedad, gracias a él se pueden entender muchos cambios y transformaciones de la sociedad actual. Solo hay que estar atento a las noticias con rigor que traen los medios tradicionales en formato impreso y/o digital.

Este cambio al que todavía la sociedad se está acostumbrando muestra aristas muy peligrosas como el cierre de determinados medios que fueron significativos en algunas ciudades, y con ellos la documentación recopilada durante años. Cada vez que un medio desaparece, la sociedad es más frágil y el mundo más peligroso. Así lo ha constatado en un estudio el profesor Lee Shaker, asistente de comunicaciones en la Universidad Estatal de Portland: "En el pasado, las muertes de las organizaciones noticiosas han puesto en peligro la perspectiva de una comunidad segura, bien informada y comprometida". Un documento de 2014 encontró una caída sustancial en el compromiso cívico tanto en Seattle como en Denver entre 2008 y 2009, después de que ambas ciudades vieron el cierre de diarios de larga duración. En Seattle, el Post-Intelligencer detuvo su edición impresa, pero continuó produciendo noticias en línea; en Denver, Rocky Mountain News se cerró (LaFrance 2017). Por tanto, los medios que nacieron para ser un contrapeso al poder, si desaparecen y ese poder pasa a estar en manos de corporaciones que no reconocen el valor de la información, excepto en el tema de las noticias falsas, entonces el mundo tendrá otra deriva.

\section{La verdad no se crea ni se destruye... aparece cuando nadie la espera}

El punto de partida podría ser esta propuesta del escritor y periodista George Orwell. En 1946 publicó el ensayo: Politics and the English Language en el que advierte a los lectores (Orwell, 1946):

El lenguaje político -y con variaciones esto es cierto para todos los partidos políticos, desde los conservadores hasta los anarquistas- está diseñado para hacer que las mentiras sean veraces y asesinas respetables, y para dar una apariencia de solidez al viento puro.

Setenta años después, unas elecciones a la presidencia de Estados Unidos en 2016 han venido a reorientar la relación de los políticos con los medios. Desde su atalaya, nada más tomar el poder y coincidiendo con manifestaciones en varias ciudades del mundo contra su política, su respuesta fue que eran los medios los culpables de haber orquestado esa situación. Los primeros días de su mandato los pasó, precisamente, atacando a la prensa y el resto de medios para marcar una línea diferente, rompiendo protocolos establecidos en la sala de prensa de la Casa Blanca y permitiendo que fueran otros medios los que tomaran el protagonismo en las ruedas de prensa.

Marcado el territorio, la propuesta fue reunirse con algunos de los grandes medios para explicarles el nuevo funcionamiento; pero sus propuestas no calaron en los periodistas. La llegada de este presidente ha sido más rupturista que la de otros. Y así lo han atestiguado algunos de los grandes periodistas de ese país. Por ejemplo, Margaret Sullivan comentó que la forma tradicional de informar sobre un presidente había muerto; al menos, como se venía haciendo hasta ahora. Para calmar las aguas, el Secretario de Prensa de la Casa Blanca, Sean Spicer comentó a un nutrido grupo de periodistas que "nuestra intención nunca es mentirle". Pero el periodismo no debe ser partidista. Debe buscar la verdad con honestidad y trasparencia, descubrir hechos noticiosos y alternativos y presentarlos como verdaderos. Eso es lo normal, lo que cada día debe plantearse un periodista.

Pero hay un iceberg que apenas está mostrando una parte de lo que oculta. El férreo control que algunas corporaciones ejercían sobre los medios, mediante la compra de acciones, ahora es más claro porque se conoce la identidad de quien controla ese grupo de accionistas. Por tanto, determinados contenidos están marcados por la propia línea editorial, por ejemplo, el pensamiento de Jeff Bezos en The Washington Post o de la familia Sulzberger en The New York Times. El torrente de información actual ayuda a crear 
climas de dudosa reputación y es entonces cuando aparecen las noticias falsas; las noticias montadas con un propósito o las noticias que deliberadamente apoyan una tendencia política, económica y/o religiosa.

En estos tiempos en los que falta una reflexión crítica de las cosas, incluida por supuesto la lectura pausada de los contenidos que ofrecen los periódicos, el auge de mentiras en la sociedad de la postverdad ha venido a alertar a los ciudadanos de que no sirve cualquier información que encuentren en las redes sociales; ni siquiera en los grandes periódicos donde se han "colado" determinados contenidos que tenían un variado interés.

¿Por qué la sociedad de la postverdad? ¿Por qué la verdad no siempre aparece como antes se la esperaba? ¿Quién maneja los hilos de la información? ¿Cómo detectar lo que es verdad de lo que no lo es en las informaciones? El punto de partida es claro: todos mentimos alguna vez. Se empieza de niños, en algún juego, y con ese sabor dulce del triunfo se aplica más tarde en la vida diaria. ¿Quién no ha mentido alguna vez? La cifra debe ser muy pequeña porque en la actualidad la mentira se ha empoderado y actúa con determinada libertad porque tiene un público que la acepta con demasiada facilidad. Lo cierto es que hay tres ejemplos claros que han constatado que la verdad ya no se presenta como antes: la votación del Brexit, en Inglaterra; el referéndum de Colombia para el proceso de Paz y las elecciones 2016 de Estados Unidos. En los tres, lo que parecía ser verdad resultó que no lo era.

Si los medios de comunicación son un reflejo de lo que hace y piensa la sociedad, las mentiras tienen su espacio. Según una información del diario británico Daily Mail, citado por Alpañés (2016), las mujeres mienten una media de tres veces por jornada mientras que los hombres lo hacen seis. El problema es que con las redes sociales todo se disemina más. Son un gran altavoz que llega a millones de personas. Y cada vez que un mensaje falso se distribuye a esos niveles, muchos empiezan a considerarlo verdadero.

Si tomamos como ejemplo, nuevamente las elecciones de Estados Unidos, descubrimos que los mensajes del actual presidente iban cargados de mentiras que los ciudadanos asumieron como si fueran verdades. Un seguimiento de sus discursos realizados por la agencia independiente PoliFact estudió 150 aseveraciones de Donald Trump: "El resultado: el $78 \%$ de sus afirmaciones eran falsas o inexistentes. En nuestro país -España- el partido del gobierno está procesado por destrucción de pruebas, es decir, por ocultar la verdad" (Alpañés, 2016, p. 23-24). Así pues, si los gobiernos mienten, los ciudadanos toman como referente ese modelo y consideran que mentir es algo normal, puesto que además de los gobiernos y los políticos, los periódicos no dicen toda la verdad, la sociedad la oculta y hasta los niños cuando pueden, disfrutan contando alguna mentira. Alguna solución se debería proponer. De momento, un ex presidente de los Estados Unidos, George W. Bush ya ha elevado su voz cuando señala que los medios de comunicación son "indispensables para la democracia" y pide su apoyo en estos tiempos diferentes en su país (Nelson, 2017):

Considero que los medios de comunicación son indispensables para la democracia. Necesitamos los medios de comunicación para que la gente como yo pueda rendir cuentas. El poder puede ser muy adictivo y puede ser corrosivo, y es importante que los medios de comunicación llamen a orden a las personas que abusan de su poder, ya sea aquí o en otro lugar.

\section{5. ¿Quién gana con las noticias falsas? El valor de las fuentes/documentación}

Hay grandes mentiras en los gobiernos actuales. Algunas se tratan de justificar en beneficio de la sociedad, o pensando que la mejor manera de atajar futuros problemas es poniendo remedio antes. El ejemplo de las guerras, citado con anterioridad, avala esta idea. La pregunta quizás no esté bien formulada, aunque políticamente siempre hay un vencedor. Lo correcto sería: ¿Por qué las sociedades actuales se dejan influenciar tanto no ya por los medios, sino por las redes sociales? ¿Por qué una simple información puede hacer tanto daño a una sociedad cuando se extiende como la pólvora en las redes sociales? También hay espacio para construir una sociedad más solidaria cuando los ciudadanos utilizan las redes para por ejemplo compartir datos sobre una enfermedad rara y eso permite salvar la vida de otras personas. No se pueden demonizar las redes sociales, pero en el tema de la información que difunden, unas veces creadas a propósito y otras sin querer, lo que se dice no es la verdad; y una vez establecida es muy difícil de dar marcha atrás.

El poder de los medios se ve debilitado, pero aún tiene un margen para mejorar. Por supuesto no se puede comparar con el crecimiento que experimentan las redes sociales y la velocidad con la que lo hacen, aunque ya hay quien viene anunciando que algunas, como Facebook, han tocado su techo. Desglosemos algunas cifras para situar este entorno (Lafrance, 2017):

El diario japonés Yomiuri Shimbun afirma que su circulación de 9 millones de copias al día la convierte 
en la más grande del mundo. En los Estados Unidos, la audiencia promedio diaria en tiempo real de CNN, Fox News y MSNBC fue de 3.1 millones de personas en 2015, según el análisis de Pew Research Center de los datos de Nielsen. Y el New York Times tenía alrededor de 1,6 millones de suscriptores digitales desde el otoño pasado.

$Y$ estas cifras tienen que competir con los 1.900 millones de usuarios activos que conviven por varias veces al día en Facebook.

Sin embargo, frente a esta avalancha de noticias falsas, tanto Facebook como Google se han implicado para frenarla. De alguna manera, ambas pueden forzar a quien tratan de introducir contenidos falsos, bien frenando su avance o bien alejándoles de los posibles beneficios a través de la publicidad. No parecen ser ellos los malos de la película. Esta nueva situación debe conducir a repensar lo que los medios de comunicación quieren. Deben saber en qué lado ponerse. Y las grandes empresas tecnológicas no tienen claro en qué nicho se ubicarían, como se pregunta Bell (2017):

¿Por qué las empresas de tecnología o sus fundadores millonarios quieren hacerlo? Ellos, más que cualquier otro interesado, tienen un interés en la integridad de la información, y la sostenibilidad del periodismo como un proyecto independiente. Ni Facebook ni Google realmente quieren emplear a periodistas, pero las instituciones de periodismo seguirán fallando debido a las condiciones adversas del mercado. Zuckerberg expresa su preocupación por el 'periodismo local' y la Iniciativa de Noticias Digitales de Google ha hecho lo mismo.

Este es un proceso con muchos altibajos. Hay quienes, incluso, proponen que cada millonario tecnológico compre alguna de las cabeceras que están pasando por malos momentos y la relancen hacia lo digital; más o menos, la experiencia de Jeff Bezos con The Washington Post. Pero no es lo mismo gestionar un periódico donde se abren muchos frentes, que en una empresa tecnológica donde los retos van en otras direcciones.

Aún está por resolver quién gana o a quién le interesan las noticias falsas. El proceso pasaría por combatir constantemente la desinformación o ver el grado de dependencia que tienen los medios de Facebook y viceversa. En ese proceso andan autores como Evangeline (2017), Filloux (2016) o Silverman (2016) que sostienen que en los últimos meses de la campaña 2016 a las elecciones en Estados Unidos, algunas noticias falsas de Facebook recibieron una mayor participación que 19 grandes medios de comunicación de ese país. Por ejemplo, Silverman (2016) apunta:

Durante los meses críticos de la campaña, 20 historias de elecciones falsas de alto rendimiento provenientes de sitios de engaño y blogs hiperpartidistas generaron 8.711.000 acciones, reacciones y comentarios en Facebook

Por su parte, Filloux considera que esta red social hasta podría prescindir de las noticias, algo que nunca han dicho sus directivos: "Debemos afrontar el hecho de que Facebook no se preocupa por las noticias en el sentido del periodismo. Las noticias representan alrededor del $10 \%$ de las fuentes de noticias del usuario promedio y las noticias pueden ser cortadas de la noche a la mañana si las circunstancias lo dictan sin ningún impacto significativo para la plataforma (Filloux, 2016). Pero no hay que olvidar que el negocio de Facebook pasa porque los usuarios permanezcan cuanto más tiempo mejor dentro de la red social. Pero, a la larga, al propio Facebook no le interesa tener que desmentir tantos errores y por eso junto con Google lanzó una campaña para frenar las noticias falsas. Hasta el propio Zuckerberg (2017) se encargó de presentar un Manifiesto que defiende otras formas de comunicar, entre ellas, frenar el avance de noticias falsas.

Hay una división, que no es tanto un enfrentamiento radical, sino una manera de plantear la información en diferentes niveles. En el fondo, todos quieren lo mismo: tener lectores, disfrutar de usuarios activos, disponer de personas en una red social. El final es el mismo cuando los medios impresos se dieron cuenta de que si conseguían más lectores, la publicidad aumentaría. Las redes sociales luchan no sólo por tener más usuarios sino porque permanezcan más tiempo. Sin publicidad, quizás estos movimientos de informaciones falsas para lograr que los usuarios estén un mayor tiempo en la red, no llegarían a producirse.

Por otra parte, hay que preguntarse si en las redes sociales hay un procedimiento que ayude a resolver estas cuestiones: ¿cuál es el proceso que se sigue para verificar una información? ¿cómo se ejecuta? ¿quién es el responsable? ¿se hace un seguimiento? No hay que olvidar que estamos en los tiempos del "todo vale". Se toma un texto de algún lugar de internet, se adapta, se mejora, o se empeora y se vuelve a publicar. Tantas veces y con tantas versiones, que el usuario ya no acierta a saber si es verdad o no. ¿Dónde están los filtros necesarios? Es posible que no existan porque la grandeza de Internet, en general y de las redes sociales, en particular, es dejar entera libertad (salvo en contadas excepciones hay censura y suelen ser sobre imágenes, no tanto sobre textos). La libertad nadie duda de que es buena, pero alguna manera de dosificarla es necesaria para evitar que se sigan creando noticias falsas y que tengan intención de beneficiar a determinadas personas y/o partidos políticos o empresas. 
Nadie duda que en los periódicos, en la radio y en la televisión se han "colado" informaciones falsas. En ocasiones, intencionadamente. Pero no ha sucedido al nivel de los últimos meses de 2016, coincidiendo con las elecciones en Estados Unidos. En parte, por el propio interés de las redes sociales para dar una versión informativa de lo que sucedía y estar mejor posicionados que el resto de medios tradicionales; $y$, en parte, por sumar usuarios y tiempo de permanencia en esas redes. Por el contrario, la seriedad de la información, el rigor periodístico, la noticia con datos, el análisis de los entornos, etc., no tuvieron grandes lectores, ni seguidores en radio y televisión. Es una muestra más de que las nuevas generaciones, algunos ya ni conocen las versiones impresas de los medios, quieren informaciones breves, dinámicas, actualizadas y sin muchos datos. Es un tipo de periodismo que no se puede llamar como tal. Al menos, como el producto que colaboró en la creación de sociedades democráticas y que ayuda a la libertad de pensamiento y de acción entre las naciones.

La pregunta clave sería ¿están interesadas las redes sociales y el resto de medios en publicar contenidos noticiosos que no sean verdaderos? ¿Cómo lo harían? ¿Qué consecuencias tendría? Ya refiere Bell, líneas atrás, que ni Google ni Facebook contratan periodistas. Por tanto, la respuesta es clara: hay un nuevo tipo de información que interesa a las nuevas generaciones de lectores/participantes en las redes sociales, y que no están dispuestos a recibir más ni mejores contenidos. Tampoco les interesa que esa información se ajuste a la realidad, ni que sea verdadera o no. La velocidad está por encima del valor real de la información. Existen propuestas por parte de los medios de comunicación para frenar el avance de las noticias falsas. Una de ellas - creada y gestionada por Le Monde: Le Décodeurs (Imagen 1) - pretende gestionar y estrangular la difusión de noticias falsas en línea (Daves, 2017):

'Decodex' es el nombre de los tres productos de comprobación de hechos del periódico francés alimentados por una base de datos de 600 sitios web considerados poco confiables y compilados por $L e$ Décodeurs, la unidad de comprobación de hechos de Le Monde, durante el último año.

Otra más reciente reunió en las jornadas MisinfoCon a un grupo de expertos con el fin de "llegar a la raíz del problema de las noticias falsas" y acabar con "La propagación de la desinformación, así como el contenido de noticias deliberadas y fabricadas en línea, ya que tienen muchas cabezas, y no existe una sola arma para defenderse de ellas". Para ello proponen arreglar el quebranto del periodismo. Además, crearon una serie de propuestas para aplicar de manera inmediata en los medios: "listas de verificación, campañas educativas, soluciones tecnológicas, compromiso con los proyectos de la comunidad, esfuerzos de diversidad y mejora de los modelos de negocio. Después de todo, las 'noticias falsas' han evolucionado para encontrar muchas cosas, incluyendo las historias que a uno no le gustan" (Wang, 2017).

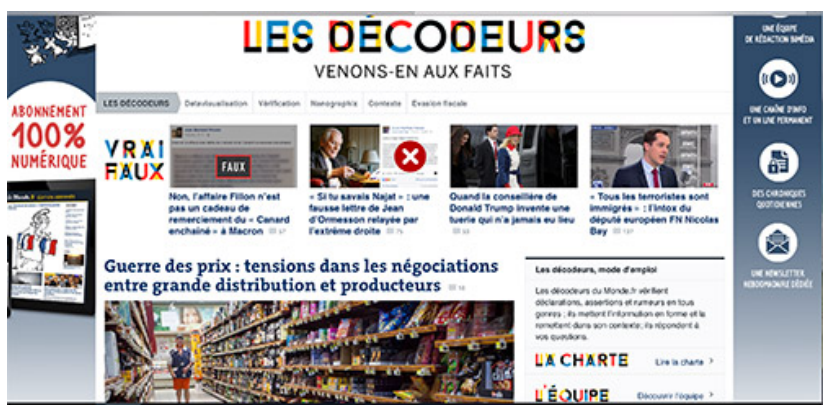

Imagen 1. Portal de acceso a Le Décodeurs

Se trata de una generación que fomenta otros valores. Su templo de saber ya no es la biblioteca sino Google, sus libros no están en la librería del barrio, sino en Amazon; su música, sus fotografías, sus juegos, su propia identidad es virtual y con ella firman parte de su legado. No esperan que una información tenga o no buenas fuentes o que el redactor haya utilizado un centro de documentación, o, más lejos aún, que haya consultado varias bases de datos. Lo que demandan las nuevas generaciones es una información que les permita estar al día en los contenidos que ellos previamente han seleccionado. Ni siquiera conciben un medio como una totalidad. Antes se leía uno el periódico, primero las secciones que más interés tenían y luego el resto.

Hoy los medios permiten suscripciones a una serie de contenidos, por lo que estamos generando una sociedad relativamente informada en una materia y con escasas perspectivas del resto. Mientras no se dé valor a las bibliotecas, la lectura, los buenos programas de radio y televisión, el mundo tomará una deriva limitada: la que interesa a las redes sociales para seguir atrayendo a sus usuarios. Mientras ellos estén cómodos y el negocio funcione, para qué cambiarlo. Esta es una sociedad democrática, liberal, participativa... Mejor en palabras del propio Zuckerberg (2017):

La exactitud de la información es muy importante. Sabemos que hay información falsa e incluso contenidos engañosos en Facebook, y tomamos esto muy en serio. Hemos presentado batallas contra el spam, pero tenemos más trabajo que hacer. Estamos procediendo con cuidado porque no siempre hay una línea clara entre los engaños, la sátira y la 
opinión. En una sociedad libre, es importante que la gente tenga el poder de compartir su opinión, aunque otros piensen que están equivocados. Nuestro enfoque se centrará menos en la prohibición de la desinformación, y más en la aparición de perspectivas adicionales, incluyendo la disputa por la precisión de un artículo.

Queda, mientras tanto, pedir que los medios tradicionales, en formatos impresos o digitales, no se rindan y sigan ofreciendo información contrastada, lo más próxima a la verdad, con apoyos documentales, con aportaciones de especialistas, con análisis en profundidad y con el rigor que siempre ha caracterizado a estos medios. La verdad no tiene dueño, pero en estos tiempos de la postverdad se agradece más que nunca a quiénes están comprometidos con ella.

El planteamiento de la información requiere de una organización general y específica. Se trata de estructurar la documentación para apoyar a los medios en su análisis y gestión. Cada paso que da el redactor, pero sobre todo el documentalista, será para tener una visión mayor en su organización y en consecuencia en su gestión. No se puede olvidar este proceso; en caso contrario, los resultados del consumo de noticias no serían productivos para las empresas.

Debemos plantear si la organización y gestión del conocimiento en la comunicación cambia sus parámetros en tiempos de la postverdad. Es este un texto para la reflexión y el análisis, y aquí una cuestión interesante a añadir sería si deberían construirse archivos de la mentira

\section{A modo de conclusiones}

La información siempre ha estado unida a tiempos de convulsión. Una redacción tranquila es sinónimo de que no pasa nada en el mundo. Pero las cosas suceden y hoy es fácil de contarlas, mucho más que en el siglo XX. Tenemos, sí, más información, pero no significa que estemos mejor informados. De hecho, una gran mentira recorre y recoge las propuestas que el actual presidente de los Estados Unidos ofrece a los medios. Dejó claro el primer día qué pensaba en los medios y cómo iba a actuar. Pasó a atacar directamente a los medios y a hacerles culpables de muchas situaciones que él mismo había generado. Ya hay en su propio partido quien está en contra de esa forma de hacer política y pide a los medios que refuercen la democracia contando la verdad.

Otra gran potencia, Rusia, viene utilizando parecidos métodos. ¿Qué cambió para llegar a esta situación? No se puede culpar a las redes sociales de que hayan tomado un camino en el que sus informaciones son suficientes para muchos de sus usuarios, y eso que para algunos, incluido el propio Zuckerberg, no es periodismo, ni Facebook es un medio ha servido para propagar con mayor rapidez informaciones falsas. Los políticos saben que las redes les facilitan una tarea que antes les costaba mucho tiempo. Pueden tomar un tema y hacerlo viral, aunque lo que se cuente no sea cierto. El caso es llegar al público masivo. ¿Qué dicen las redes sociales? Mientras tengamos usuarios que estén interesados en esos temas, adelante. Pero esta situación tampoco es buena para las redes, de ahí que también estén persiguiendo contenidos que no se ajustan a la realidad. Algunos van más lejos, como Le Monde, que ha creado un sitio para determinar qué otros sitios de Internet "trafican" con informaciones falsas. La mejor solución para frenar las noticias falsas es la que están proponiendo algunos editores de prensa a través de los fact-chequers o verificadores de hechos. Para ellos, los verificadores desempeñan un papel importante y necesario a la hora de comprobar la información. Ese es el reto. Difícil porque los recortes en los medios han dejado que se pierdan algunas funciones, como la del revisor de los textos.

La sociedad de la postverdad ya no es una responsabilidad de los medios, como en el siglo XX. Ahora muchas mentiras se mueven por Internet con el peligro de que otros las copien, las difundan y las hagan virales. La mejor manera de estar informados de verdad siguen siendo los medios tradicionales de toda la vida y los nuevos medios digitales que se han ganado el derecho a contar la verdad. Las redes sociales son casi más rápidas que el periodismo digital, pero no tan seguras. $Y$ esto parece que no va a cambiar de inmediato.

Sin un control por parte de los documentalistas y gestores de la información será difícil que el conocimiento que se genera en estas redes sociales tenga un valor de futuro. La inmediatez de los hechos y las informaciones que publican estas redes es su principal motivación. El consumo de noticias decrece a pasos agigantados en los medios y se hace más activo en las redes sociales, por este motivo el conocimiento que antes ofrecían los medios terminará por perderse si la tendencia de consumo de información continua dentro de las redes sociales.

\section{Referencias}

Alpañés, E. (2016). Bienvenido a la sociedad postverdadera. // Yorokobu. 79, 22-24.

Bell, E. (2017). How Mark Zuckerberg could really fix journalism. 21/02/2017. http://www.cjr.org/tow_center/mark-zuckerberg-facebook-fix-journalism.php?utm_source=Daily +Lab+email+list\&utm campaign $=81 \mathrm{f} 5 \mathrm{~b} 61 \mathrm{e} 0 \mathrm{~d}$-dailylabemail3\&utm_medium =e-mail\&utm_term $=0$ _d68264fd5e$81 \mathrm{f}$ b61e0̄-395887489 (2017-04-10). 
Davies, J. (2017). Le Monde identifies 600 unreliable websites in fake-news crackdown. 25/01/2017. http://digiday.com/uk/le-monde-identifies-600-unreliable-websitesfake-news-crackdown/ (2017-04-10).

Evangeline (2017). Hacking the Facebook news problem. 16/02/2017. https://medium.com/global-editors-network/ hacking-the-facebook-news-problem-85eb31f823a1\#.t1 dbklg01 (2017-04-10).

Filloux, F. (2016). Facebook's Walled Wonderland Is Inherently Incompatible With News. 05/12/2016. https://mon daynote.com/facebooks-walled-wonderland-is-inhrentlyincompatible-with-news-media-b145e2d0078c\#.ro8n035 mq (2017-04-10).

Herman, E. S.; Chomsky, N. (1998). Manufacturing consent the political economy of the mass media. London: Arrow Books.

Lafrance, A. (2017). The Mark Zuckerberg Manifesto Is a Blueprint for Destroying Journalism. 17/02/2017. http://www.theatlantic.com/technology/archive/2017/02/ the-mark-zuckerberg-manifesto-is-a-blueprint-for-destroying-journalism/517113/ (2017-04-10).

Marcos Recio, J.C.; García-Alonso, P.; Parra, D.; Edo, C.; Flores Vivar, J. (2008). Estrategias y perspectivas documentales en la información digital. Sevilla: Ámbitos, 2008. http://www.redalyc.org/articulo.oa?id=16812702001 (2017-04-10)

Nelson, L. (2017). Bush breaks with Trump, calls media 'indispensable to democracy'. 27/02/2017. http://www.politico.com/story/2017/02/george-w-bush-trump-media235430?utm_source=Daily+Lab+email+list\&utm_campaign $=386 \mathrm{~d} 129 \mathrm{~d} 80$-dailylabemail $3 \& u t m \_m e-$ dium=email\&utm term=0 d68264fd5e-386d129d80395887489 (2017-04-10).

ORWELL, G. (1946). Politics and the English Language. London: Horizon, april 1946.
Salvador Benítez, A; Sánchez Vigil, JM (2016). La fotografía como documento informativo en las webs de los Ministerio Españoles: Acceso, visibilidad, funcionalidad y políticas de uso. // Revista Española de Documentación Científica, 39:2.

Silverman, G. (2016). This Analysis Shows How Viral Fake Election News Stories Outperformed Real News On Facebook. 16/11/2016. http://www.buzzfeed.com/craigsilverman/viral-fake-election-news-outperformed-realnews-on-facebook?utm term=.xe4W2DGeb\#.ng36e AQI2 (2017-04-10).

Tanz, J. Journalism Fights for Survival in the Post-Truth Era. 14/02/2017. http://www.wired.com/2017/02/journalismfights-survival-post-truth-era/ (2017-04-10).

Tyner, J. (2017). Dear news media: Create news for people who have never read a newspaper. 21/02/2017. https://medium.com/media-center-lab/dear-news-mediacreate-news-for-people-who-have-never-read-a-newspaper-8f94845f9008\#.mpds2s0ov (2017-04-10).

Wang, S. (2017). Shan Wang. Getting to the root of the "fake news" problem means fixing what's broken about journalism itself. 27/02/2017. http://www.niemanlab.org/2017/02/getting-to-the-root-of-the-fake-news-problem-means-fixing-whats-broken-about-journalism-itself/ ?utm_source=Daily+Lab+email+list\&utm_campaign $=386$ d129d80-dailylabemail3\&utm_medium=email\&utm_ter $m=0$ d68264fd5e-386d129d80-395887489 (2017-0410)

Zuckerberg, M. (2017). Building Global Community. 16/02/2017. http://www.facebook.com/notes/mark-zucker berg/building-global-community/10154544292806634 (2017-04-10).

Enviado: 2017-04-10. Segunda versión: 2017-06-21. Aceptado: 2017-09-14. 
